\section{BJOS

Volume 16

2017

e17068

\title{
Biological and mechanical degradation affecting the surface properties of aesthetic restorative
}

Bianca Medeiros Maran ${ }^{1}$, Fabiana Scarparo Naufel ${ }^{2}$, Andréia Bolzan de Paula ${ }^{3}$, Giovana Spagnolo Albamonte Araújo ${ }^{3}$, Regina Maria Puppin-Rontani ${ }^{4}$

1 DDS, MS, PhD student Universidade Estadual do Oeste do Paraná - UNIOESTE, School of Dentistry, Department of Restorative Dentistry, Cascavel, Paraná, Brazil

${ }^{2} \mathrm{DDS}, \mathrm{MS}, \mathrm{PhD}$, adjunctive professor, Universidade Estadual do Oeste do Paraná - UNIOESTE, School of Dentistry, Department of Restorative Dentistry, Cascavel, Paraná, Brazil

${ }^{3} \mathrm{DDS}, \mathrm{MS}, \mathrm{PhD}$, Universidade Estadual de Campinas, Faculdade de Odontologia de Piracicaba FOP/UNICAMP, School of Dentistry, Department of Dental Materials, Piracicaba, São Paulo, Brazil

${ }^{4} \mathrm{DDS}, \mathrm{MS}, \mathrm{PhD}$, adjunctive professor, Universidade Estadual de Campinas, Faculdade de Odontologia de Piracicaba - FOP/ UNICAMP, School of Dentistry, Piracicaba, São Paulo, Brazil

Corresponding author: Bianca Medeiros Maran, Engenharia 464 -

Universitário - Cascavel, PR, zip code: 85819-190 - Brazil.

Phone: +55 45 99968-3042

Email: medeiros.bianca@hotmail.com

Received: June 25, 2017

Accepted: September 20, 2017
Aim: To evaluate the roughness ( $\mathrm{Ra})$, Knoop hardness $(\mathrm{KHN})$ and change of color $(\triangle \mathrm{E})$ of esthetic restorative materials (Filtek Z350-composite nanoparticle; Empress Direct-composite nanohybrid and IPS e.Max-ceramic) subjected to contact with the Streptococcus mutans biofilm (biological degradation) associated with abrasion generated by tooth brushing (mechanical degradation). Methods: Ten specimens of each material were prepared, and the surface properties initial were evaluated. All specimens were exposed to Streptococcus mutans inoculum; after 7 days, surface properties were evaluated. The specimens were submitted to a 30,000 toothbrushing cycles, using a toothpaste slurry, then, surface properties were evaluated again. Data were analyzed by Proc-Mixed, One-way ANOVA, Tukey-Kramer and Tukey's tests $(\alpha=0.05)$. Results: At the baseline, ceramic showed the highest Ra and KHN values; after the biological degradation the composites showed increased $\mathrm{Ra}$, but KHN did not change; after the mechanical degradation, Empress showed decreased Ra and Z350 showed similar Ra, the KHN increased to both composites, and all materials had increased lightness after the mechanical degradation. Conclusions: The results suggest that, when exposed to Streptococcus mutans biofilm and toothbrush abrasion, the ceramics undergoes minimal degradation and the composites exhibited variable degradation, depending on the composition of the material. Keywords: Biofilms. Surface properties. Dental Materials. 


\section{INTRODUCTION}

All restorative materials are susceptible to degradation. The degradation of restorative materials can be caused by low pH because of the cariogenic biofilm, consumption of acidic drinks or foodstuffs, and toothbrushes and the water present on saliva as well other components of the saliva?

Tooth brushing is the most used and efficient mechanical method to remove dental biofilm from all accessible tooth surfaces ${ }^{2}$. Published studies have shown that this method may cause tooth and composite abrasion. This degradation process may lead to several drawbacks, such as an increase in wear and surface roughness, softening and a decrease in the hardness of dental materials ${ }^{3-5}$. Over time, intraoral degradation also interferes with the fracture strength of the material, culminating in a lower durability of the restoration in the long term ${ }^{6}$. Surface texture, gloss and color are also included among the important characteristics that determine the aesthetic effect of these composite restorations, and they are also influenced by the intraoral surroundings $s^{7,8}$.

It is important to know about this process, because the search for dental esthetics has been one of the main reasons why patients seek a dentist. Thus, the need for tooth-colored fillings has increased, decreasing the use of metal restorations and dental amalgam fillings or cast metal, unlike the use of aesthetic materials, such as composite and ceramics, which have been increasingly used?

Ceramics are considered the most inert of all dental materials used for restorations, composed of metal elements (aluminum, calcium, lithium, magnesium, potassium, sodium, lanthanum, tin, titanium and zirconium) and non-metal substances (silicon, boron, fluorine and oxygen), and characterized by two phases: a crystalline phase surrounded by a vitreous layer ${ }^{10}$. So far, little information about surface degradation by biofilm is available in the literature. Some studies have evaluated the interaction between biofilm and ceramics, but they verified only the biofilm characteristics instead of the biodegradation produced on the material surfaces ${ }^{11,12}$.

Composites are currently the most used material in the field of restorative dentistry. Basically, these materials are composed of three chemically different components: a polymeric matrix of dimethacrylate monomers, filler particles (dispersed phase) and an organosilane, which is a coupling agent that bonds the fillers to the polymeric matrix ${ }^{13}$.

In this context, nanotechnology, consisting of nanofillers, has emerged in the dental market ${ }^{14}$. This technology came with the intention of improving the electrical, chemical, mechanical and optical properties of restorative materials with advantages such as less toothbrush abrasion, greater hardness and better translucency, polish, gloss and opacity options being used for restorations of anterior and posterior teeth; as a result, studies have been done to prove these characteristics ${ }^{15,16}$.

The nanohybrid composite IPS Empress Direct promises similar aesthetics to those made of ceramics in addition to the advantages of easy handling of the composite (Ivoclar Vivadent).

Therefore, it becomes interesting to compare the IPS Empress Direct composite with a 100\% nanofiller resin such as Z350 (3M ESPE St. Paul, MN, USA), as well as with the 
ceramics IPS e.Max (IPS Empress; Ivoclar-Vivadent, Schaan, Liechtenstein), considering the material that undergoes minimal degradation.

Thus, the aim of this study was to test the hypothesis that aesthetic restorative materials submitted to the Streptococcus mutans biofilm associated with brushing abrasion would differ in surface stability to degradation, depending on their composition.

\section{MATERIALS AND METHODS}

\section{Specimen Preparation}

10 specimens of each material tested (described in Table 1) were fabricated using silicon molds (Express 3M ESPE, St. Paul, Minn, USA) of $8 \mathrm{~mm}$ in diameter and $2 \mathrm{~mm}$ deep, with the exception of the ceramics. Composite materials were inserted in a mold using incremental technique and covered with polyester strips and a glass slide to obtain a smooth flat surface. All specimens light cured using a LED light unit (Elipar Freelight, 3M ESPE, St. Paul, MN, USA) for 40 s on the top surface. The light intensity of the curing $\left(1000 \mathrm{~mW} / \mathrm{cm}^{2}\right)$ device was checked with a curing light meter (Hilux Dental Curing Light Meter, Benlioglu Dental Inc., Demetron, Ankara, Turkey). Then, specimens were storage for $24 \mathrm{~h}$ in $100 \%$ relative humidity at $37^{\circ} \mathrm{C}$, and then, they were polished with sequential abrasive discs (Soflex Pop-On, 3M ESPE, St. Paul, MN, USA).

Table 1. Material, composition, color and batch of the tested materials.

\begin{tabular}{|c|c|c|c|c|c|}
\hline & Materials & Composition & Mean Filler Size & Color & Batch \# \\
\hline \multirow{2}{*}{ Composite } & $\begin{array}{l}\text { Filtek Z350 XT } \\
\text { (3M ESPE St. } \\
\text { Paul, MN, USA) }\end{array}$ & $\begin{array}{c}\text { Bis-GMA (1-10 wt\%); UDMA } \\
\text { (1-10 wt\%); TEGDMA (<5 } \\
\text { wt\%); Bis-EMA (1-10 wt\%); } \\
\text { PEGMA (< } 5 \text { wt\%) } \\
\text { Silica, zirconia, zirconia/ } \\
\text { silica (78.5 wt\%) }\end{array}$ & $\begin{array}{l}0.6-1.4 \mu \mathrm{m} \\
\text { (cluster) } \\
5-20 \mathrm{~nm} \\
\text { (nanofiller) }\end{array}$ & A3E & 1124300109 \\
\hline & $\begin{array}{l}\text { IPS Empress } \\
\text { Direct (Ivoclar- } \\
\text { Vivadent, } \\
\text { Schaan, } \\
\text { Liechtenstein) }\end{array}$ & $\begin{array}{l}\text { UDMA }(10-<20 \text { wt } \%) ; \\
\text { TEGDMA (3-<5 wt\%); } \\
\text { Bis-GMA (2.5-<3 wt\%) } \\
\text { Barium glass, ytterbium } \\
\text { trifluoride, mixed oxide, } \\
\text { silicon dioxide and } \\
\text { copolymer (77.5-79 wt\%) } \\
\text { Additives, catalysts, } \\
\text { stabilizers and } \\
\text { pigments (<1.0 wt\%) }\end{array}$ & 0.4 to $0.7 \mu \mathrm{m}$ & A3E & N32078 \\
\hline Ceramic & $\begin{array}{l}\text { IPS e.Max } \\
\text { (Ivoclar- } \\
\text { Vivadent, } \\
\text { Schaan, } \\
\text { Liechtenstein) }\end{array}$ & $\begin{array}{c}\mathrm{SiO}_{2}, \mathrm{Li}_{2} \mathrm{O}, \mathrm{K}_{2} \mathrm{O}, \mathrm{MgO}, \mathrm{ZnO} \\
\mathrm{Al}_{2} \mathrm{O}_{3}, \mathrm{P}_{2} \mathrm{O}_{5} \text { and others } \\
\text { oxides }\end{array}$ & - & A3E & P82207 \\
\hline
\end{tabular}


Ceramic specimens were fabricated with the same dimensions of the composite, in a prosthetic laboratory using the pressing process in an oven (Programat P500-Ivoclar Vivadent, Schaan, Liechtenstein), and they were glazed.

Then, all specimens were stored in water at $37^{\circ} \mathrm{C}$ for $24 \mathrm{~h}$ for the evaluation of the baseline properties.

\section{Measurements of Surface Roughness}

The surface roughness (Ra) was measured in a rugosimeter (Surfcorder SE 1700, Kosaka, Tokyo, Japan) at a constant speed of $0.5 \mathrm{~mm} / \mathrm{s}$ with a load of $0.7 \mathrm{mN}$. The cut-off value was set at $0.25 \mathrm{~mm}$ to maximize the filtration of the surface waviness. The Ra values for each specimen were taken across the diameter over a standard length of $1.25 \mathrm{~mm}$. The mean surface roughness values $(\mu \mathrm{m})$ of the specimens were obtained from three successive measurements of the center of each disk, in different directions $\left(45^{\circ}\right)$. A calibration was done periodically to check the performance of the surface roughness-measuring instrument.

\section{Measurements of Hardness}

Three Knoop hardness (KHN) indentations were made on the surface of the specimen under a load of $50 \mathrm{~g}$ for $10 \mathrm{~s}$ (HMV-2, Shimadzu, Tokyo, Japan). The KHN for each specimen was recorded as the average of the three readings distant $100 \mu \mathrm{m}$ each other.

\section{Measurement of Color}

The readings were performed using a spectrophotometer (CM-700d, Konica Minolta, Osaka, Japan). Initially, the ambient light was calibrated in a light cabin, (GTI Mini Matcher MM1e, GTI Graphic Technology Inc., Newburgh, NY, USA), and the specimens were positioned in a sample carrier for the baseline readings. The parameters $L^{*}, a^{*}$ and $b^{*}$ from the color space, referred to as $\operatorname{CIELAB}\left(L^{*}, a^{*}, b^{\star}\right)$, were recorded. The $L^{*}$ indicates lightness ( $L^{*}+=$ lightness and $L^{*}-=$ darkness), the $a^{*}$ coordinate represents the red/green range ( $a^{\star}+=$ redness and $a^{*}-=$ greenness $)$ and the $b^{*}$ coordinate represents the yellow/blue range ( $b^{\star}+=$ yellowness and $b^{*}-=$ blueness). The $L^{*} a^{*} b^{\star}$ system allows the numeric definition of a color, as well as the difference between two colors using the following formula: $\Delta \mathrm{E}=\left[(\Delta \mathrm{L})^{2}+(\Delta \mathrm{a})^{2}+(\Delta \mathrm{b})^{2}\right] 1 / 2$. The data acquisition was performed by a microcomputer using On Color QC Lite software (Konica Minolta, Osaka, Japan).

\section{Biofilm Growth - Biological degradation}

After the measurements of surface roughness, hardness and color, the all the specimens were sterilized for $4 \mathrm{~h}$ in an ethylene oxide chamber (Ferlex, São Paulo, SP, Brazil). A Streptococcus mutans (UA 159) strain was obtained from the culture of the Department of Microbiology and Immunology, Piracicaba Dental School, University State of Campinas. To prepare the inoculums, the Streptococcus mutans was first grown on mitis salivarius agar plates (Difco Laboratories, Sparks, MI, USA) at $37^{\circ} \mathrm{C}$ for $24 \mathrm{~h}$ in an environment supplemented with $5 \% \mathrm{CO}_{2}$.

Subsequently, single colonies were inoculated into $5 \mathrm{~mL}$ of brain-heart infusion (BHI) broth (Difco Laboratories, Detroit, MI, USA) and incubated at $37^{\circ} \mathrm{C}$ for $24 \mathrm{~h}$. The spec- 
imens were exposed under static conditions to $25 \mu \mathrm{L}$ of Streptococcus mutans inoculums adjusted to an optical density of 0.6 at $550 \mathrm{~nm}$ (approximately $8 \times 1011 \mathrm{CFU} / \mathrm{mL}$ ), and after 2 hours at room temperature the non-adhering cells were removed by washing twice with $0.9 \% \mathrm{NaCl}$ solution (saline).

A single material disk was inserted in each well of 48-well polystyrene plates (Nunc multidish, Sigma, St. Louis, MO, USA) with $2 \mathrm{~mL}$ of sterile, fresh BHI broth with the addition of $1 \%$ sucrose $(\mathrm{wt} / \mathrm{vol})$. The bacterial accumulation occurred at $37^{\circ} \mathrm{C}$ in an environment supplemented with $5 \% \mathrm{CO} 2$, developing 7-day-old biofilms. The medium was renewed every $48 \mathrm{~h}$. At the end of the experimental period, the specimens were ultrasonically (UNIQUE 1400, Indaiatuba, SP, Brazil) washed for 10 minutes, and soon after the measurements were repeated. Three-body abrasion test - Mechanical degradation.

\section{Three-body Abrasion Test - Mechanical degradation}

After biological degradation, the tooth brushing test was conducted at 250 cycles/min for 30,000 cycles with a $200 \mathrm{gF}$ load. The Oral B Pró Saúde toothpaste (Procter \& Gamble, São Paulo, SP, Brazil) was diluted in distilled water (1:2) and used as an abrasive third body. Specimens were washed in an ultrasonic bath for 10 min and gently dried with absorbent paper. Then, three final surface roughness readings were taken from each specimen in the opposite direction to that of the tooth brushing movement; Knoop hardness and color were also evaluated as previously reported after mechanical degradation using the same pattern described above.

\section{Statistical Analysis}

For $\mathrm{Ra}, \mathrm{KNH}$ and $\mathrm{L}^{*}$, after the exploratory data analysis and selection of the best covariance structure, data were analyzed by means of mixed models (Proc-Mixed) and Tukey-Kramer test $(\alpha=0.05)$. The data of hardness suffered logarithmic transformation to meet the assumptions of a parametric analysis. For $\Delta \mathrm{E}$, after the exploratory analysis the data were analyzed by One-way ANOVA and Tukey's test $(\alpha=0.05)$.

\section{RESULTS}

There was a significant difference among the materials studied $(p<0.0001-$ for all the variables analyzed) and between the degradation methods (baseline/biological biodegradation/mechanical degradation) (for Ra and KHN: $p<0.0001$; for $L^{*}: p=001$; for initial $\Delta E: p=0005)$; in addition, there was significant difference for the interaction between the three studied factors (for Ra: $p<0.0001$; for $K H N$ : $p=0.0327$; for $L *: p=0.05$ ).

Table 2 shows the Ra averages found by different materials and different degradation processes. At baseline, e.Max showed the highest roughness and the Empress and Z350 composite showed very low and similar roughness. After biological degradation, the Ra values of e.Max increased still remaining statistical similarity to the baseline, but it was showed a significant increase for Z350 and Empress composite, being that Z350 showed the lowest roughness. However, after mechanical degradation, the roughness of Z350 remained similar to the biological degradation and higher than baseline values; for Empress and e.Max, Ra was smaller than biological values; being statistically similar to the baseline values for e.Max, but for Empress it was lower than those obtained after biological degradation but higher than baseline values (Table 2). 
Table 2. Means (standard deviations) of surface roughness $(\mathrm{Ra})(\mu \mathrm{m})$ for the different experimental conditions.

\begin{tabular}{lccc}
\hline Materials & Baseline & Biological biodegradation & Mechanical degradation \\
\hline Z350 & $0.26(0.09) \mathrm{Bb}$ & $1.51(1.08) \mathrm{Ab}$ & $1.48(0.70) \mathrm{Aab}$ \\
\hline Empress & $0.24(0.07) \mathrm{Cb}$ & $2.71(0.43) \mathrm{Aa}$ & $0.86(0.34) \mathrm{Bb}$ \\
\hline e.Max & $2.60(0.71) \mathrm{ABa}$ & $3.26(0.98) \mathrm{Aa}$ & $2.20(0.79) \mathrm{Ba}$ \\
\hline
\end{tabular}

Means followed by different capital letters in the same line and small letters in the same column were significantly different $(p<0.05)$.

Table 3 shows the KHN values obtained for different materials and degradation models. At baseline, Empress and Z350 composite showed the lowest and similar KHN values. After the $S$ mutans degradation, it can be observed that all materials experienced a decreasing on KHN values. However, in a descending significant order it can be observed that e.Max showed the highest KHN values followed by Empress and Z350. After the mechanical degradation, the hardness increased for Z350 and remained similar to the biological degradation values for Empress. In all conditions, baseline, biodegradation and mechanical degradation exposition, e.Max showed the highest KHN values (Table 3)

Table 3. Means (standard deviations) of the Knoop hardness (KHN) for the different experimental conditions.

\begin{tabular}{lccc}
\hline Materials & Baseline & Biological biodegradation & Mechanical degradation \\
\hline Z350 & $62.1(24.0) \mathrm{Bb}$ & $51.6(15.38) \mathrm{Bc}$ & $82.38(17.8) \mathrm{Ab}$ \\
\hline Empress & $82.2(15.8) \mathrm{Ab}$ & $80.4(13.5) \mathrm{Ab}$ & $106.2(16.7) \mathrm{Ab}$ \\
\hline e.Max & $811.7(139.9) \mathrm{Aa}$ & $656.8(105.6) \mathrm{Aa}$ & $757.8(151.1) \mathrm{Aa}$
\end{tabular}

Means followed by different capital letters in the same line and small letters in the same column were significantly different $(p<0.05)$.

Table 4 shows the $\Delta$ E values for different materials submitted to different degradation models. After the biological biodegradation, the Empress composite showed the lowest $\Delta \mathrm{E}$, similar to e.Max values. There was no statistical difference between all materials studied after the mechanical degradation (Table 4).

Table 4. Means (standard deviations) of color change $(\Delta E)$ for the different experimental conditions

\begin{tabular}{lcc}
\hline Materials & Biological biodegradation & Mechanical degradation \\
\hline Z350 & $2.8(1.0) \mathrm{a}$ & $1.9(0.5) \mathrm{a}$ \\
\hline Empress & $2.1(0.5) \mathrm{b}$ & $1.2(0.4) \mathrm{a}$ \\
\hline e.Max & $3.0(0.6) \mathrm{a}$ & $1.7(1.1) \mathrm{a}$ \\
\hline
\end{tabular}

Groups denoted by a different letter represent significant difference $(p<0.05)$.

Table 5 shows the values obtained for lightness of the materials submitted to different degradation models.

All materials studied showed the same performance when submitted to different degradation methods. At baseline, all materials showed similar lightness pattern. However, the exposition to $S$ mutans biofilm provided the lowest lightness for Empress 
Table 5. Means (standard deviation) of lightness $\left(L^{*}\right)$ for the different experimental conditions.

\begin{tabular}{lccc}
\hline Materials & Baseline & Biological biodegradation & Mechanical degradation \\
\hline Z350 & $72.96(0.23) \mathrm{Ba}$ & $72.78(0.69) \mathrm{Ba}$ & $73.50(0.29) \mathrm{Aa}$ \\
\hline Empress & $68.59(0.53) \mathrm{Ba}$ & $71.81(0.71) \mathrm{Bb}$ & $72.50(0.51) \mathrm{Ab}$ \\
\hline e.Max & $72.60(0.53) \mathrm{Ba}$ & $73.18(0.55) \mathrm{Ba}$ & $73.30(0.51) \mathrm{Aab}$ \\
\hline
\end{tabular}

Means followed by different capital letters in the same line and small letters in the same column were significantly different $(p<0.05)$.

when compared with e.Max and Z350. A significant increase on lightness can be observed for all materials studied after mechanical degradation, although the highest values were observed for Z350 and the lowest for Empress. e.Max showed intermediary lightness (Table 5).

\section{DISCUSSION}

Aesthetic restorative materials are prone to a gradual degradation process in the oral cavity because of $\mathrm{pH}$ changes (chemical or bacterial action), temperature, chewing and brushing, depending on the composition of the restorative material ${ }^{15,17,18}$.

This study revealed that the composites showed similar average roughness after polishing. After biological degradation, the composites show different variations of roughness, which may depend on the hydrolytic stability of the polymer matrix ${ }^{15,16}$. According to Sarkar ${ }^{19}$ (2000) these changes are due to the absorption and diffusion of water and organic acids from the bacterial metabolism, internal resin matrix, interfaces between the inorganic particles, pores and other defects. The greater increase in the roughness of the composite Empress compared to Z350 can be attributed to the fact that the second one is a composite which has only nanoparticles particles as fillers, with less interstitial spacing of the matrix, which decreases its hydrolysis; in addition, we should mention the presence of Bis-EMA, a hydrophobic monomer, which favors the hydrolytic stability ${ }^{13,16,20,21}$.

At baseline, the ceramics showed higher roughness than the polished composites, which is due to the irregularities in the surface from the resulting glazing process. After the biological biodegradation, there was no significant variation in the surface roughness of the ceramics, which may be due to the stability of the material, as it is considered the most inert dental material ${ }^{10}$. These results are in agreement with the study of Padovani et al. ${ }^{1}$ The final roughness of the ceramics was comparable to the original, which is in agreement with studies evaluating resistance to toothbrush abrasion ${ }^{8,22}$

The surface hardness of Z350 remained statistically similar after biological degradation; the presence of the TEGDMA monomer is justified in both composites, which increases the degree of conversion, reducing leaching and softening ${ }^{10,21}$. Hardness becomes an important parameter to measure the performance of materials in the oral environment, being correlated with the resistance to compression and abrasion, and it indirectly reflects the rate of polymerization of the material ${ }^{5}$. Materials with decreased hardness have reduced longevity and may require early replacement of the restoration ${ }^{5,23}$. 
The hardness of the Z350 composite was lower than the Empress after the biological biodegradation, and this can be attributed to differences in size and distribution of the fillers on these materials ${ }^{4,24}$; beyond the aforementioned factor, it can be speculated that this is the association of the consequent hydrolysis of the polymeric matrix with the inorganic framework differences of the studied composites ${ }^{24}$.

The ceramic, showed higher hardness, in all degradation methods than the composites studied, which is due to their glass character, as there is the coalescence of the particles and higher solid density in the sintering process ${ }^{1,10}$. The nanofilled composite may be prone to absorbing liquids because of the greater contact area-load matrix, and this interface is more susceptible to fluid accumulation in the bacterial biofilm, or alternatively, the spaces resulting from the presence of the imperfect engagement of charged particles in the polymeric matrix. Spaces or "microvoids" in the polymeric matrix can increase the retention of acids and thereby increase the degradation of Z35024.

In the oral cavity, the deleterious effects of the biodegradation are generally associated with toothbrush abrasion, as the abrasiveness of the toothpaste along with the toothbrush may promote the displacement of charged particles, which is directly proportional to the size of these effects ${ }^{25}$. The hardness of the composite Z350 increased, this can be attributed to the process of maturation or late polymerization of the composite ${ }^{26}$, and that the nano-sized loads have greater contact surface with the organic phase, improving the hardness of the material27.

The Empress composite showed decreased roughness after the mechanical degradation, but not returning to equivalent values to the baseline; this may be due to the losses of larger particles, which weakens the softened matrix and enhances the abraded mass of the polymer, removing the softened layer ${ }^{13,20}$. The roughness of Z350 remained similar to that observed after the biological degradation, and greater than at the baseline, which can be attribute to the effect of the bristles of the toothbrush atop the smaller interstitial space in the polymeric matrix, which could result in a higher abrasion resistance ${ }^{16}$.

The lightness and stability of the color, important properties of aesthetic restorative materials, are influenced by various factors such as the composition of the inorganic portion, diet, habits or even the organic matrix. The sensitivity of the human eye to detect color variation translates to $\Delta \mathrm{E}>3.3$; thus, the color changes were imperceptible to human sensitivity22,28,29. However, analysis of the CIELAB color scale coordinates $(L *, a *$, and $b *)$ showed significant changes in the values of $L^{*}$. The lightness is the ability of the material to reflect direct light and is closely related to the surface characteristics of the material, ranging from light (100) to dark (0) $)^{8,30}$.

After the mechanical degradation, there were increases in the lightness for all materials studied, probably the optical changes that occurred reflect physical and chemical reactions: i) internal - such as hydrolysis - or ii) in the surface - such as increased roughness -, as these affect the lightness through changes in the refractive index and reflection, respectively ${ }^{28}$, since the specimens were not exposed to any coloring agent and there was standardization of the thickness of the specimens. 
The biodegradation provided on composite materials as $\mathrm{Ra}$, was recovered after mechanical degradation for all materials. However, for hardness, only Empress Direct has recovered that after bio and mechanical degradation. Color was significantly affect after mechanical degradation for all materials studied.

Based on the experimental conditions described, the results showed that the degradation process associated with toothbrush abrasion promoted increased roughness of the nanoparticulate composite Z350; the nanohybrid composite Empress exhibited less variations in roughness and hardness than that of the nanoparticle; finally, the ceramic e.Max was more stable and resistant to degradation in the oral environment.

\section{Acknowledgements}

This investigation was supported by the Romanini dental prosthesis laboratory. Address: Avenida Rio de Janeiro, 1306, 86010150 - Londrina - PR E-mail: contato@romanini.com.br

Espaço da Escrita/Coordenadoria Geral da UNICAMP

\section{References}

1. Padovani G, Fucio S, Ambrosano G, Sinhoreti M, Puppin-Rontani R. In situ surface biodegradation of restorative materials. Oper Dent. 2014;39(4):349-60. doi: 10.2341/13-089-C. PubMed PMID: 24555699

2. Srivastava N. A comparative evaluation of efficacy of different teaching methods of tooth brushing in children contributors. J Oral Hyg Health. 2013;01(03). doi: 10.4172/2332-0702.1000118.

3. da Silva MA, Fardin AB, de Vasconcellos RC, Santos Lde M, Tonholo J, da Silva JG, Jr., et al. Analysis of roughness and surface hardness of a dental composite using atomic force microscopy and microhardness testing. Microsc Microanal. 2011;17(3):446-51. doi: 10.1017/S1431927611000250. PubMed PMID: 21492501

4. Da Silva E, de Sá Rodrigues C, Dias D, da Silva S, Amaral C, Guimarães J. Effect of toothbrushing-mouthrinse-cycling on surface roughness and topography of nanofilled, microfilled, and microhybrid resin composites. Oper Dent. 2014;39(5):521-9.

5. Barbosa RP, Pereira-Cenci T, Silva WM, Coelho-de-Souza FH, Demarco FF, Cenci MS. Effect of cariogenic biofilm challenge on the surface hardness of direct restorative materials in situ. J Dent. 2012;40(5):359-63. doi: 10.1016/j.jdent.2012.01.012. PubMed PMID: 22326721.

6. Wei Y-j, Silikas N, Zhang Z-t, Watts DC. Hygroscopic dimensional changes of self-adhering and new resin-matrix composites during water sorption/desorption cycles. Dent Mater. 2011;27(3):259-66.

7. Sarkis E. Color change of some aesthetic dental materials: Effect of immersion solutions and finishing of their surfaces. Saudi Dent J. 2012;24(2):85-9. doi: 10.1016/j.sdentj.2012.01.004.

8. Roselino Lde M, Cruvinel DR, Chinelatti MA, Pires-de-Souza Fde C. Effect of brushing and accelerated ageing on color stability and surface roughness of composites. J Dent. 2013;41 Suppl 5:e54-61. doi: 10.1016/j.jdent.2013.07.005.

9. Correa MB, Peres MA, Peres KG, Horta BL, Barros AD, Demarco FF. Amalgam or composite resin? Factors influencing the choice of restorative material. J Dent. 2012;40(9):703-10. doi: 10.1016/j.jdent.2012.04.020.

10. Anusavice K. Degradability of dental ceramics. Adv Dent Res. 1992;6(1):82-9. 
11. Rosentritt M, Sawaljanow A, Behr M, Kolbeck C, Preis V. Effect of tooth brush abrasion and thermo-mechanical loading on direct and indirect veneer restorations. Clin Oral Investig. 2015;19(1):53-60.

12. Rashid $\mathrm{H}$. The effect of surface roughness on ceramics used in dentistry: A review of literature. Eur J Dent. 2014;8(4):571.

13. Ferracane JL. Resin composite--state of the art. Dental materials : official publication of the Acad Dent Mater. 2011;27(1):29-38. doi: 10.1016/j.dental.2010.10.020.

14. Ozak ST, Ozkan P. Nanotechnology and dentistry. Eur J Dent. 2013;7(1):145-51.

15. De Fúcio S, de Paula AB, de Carvalho FG, Feitosa VP, Ambrosano G, Puppin-Rontani RM. Biomechanical degradation of the nano-filled resin-modified glass-ionomer surface. Am J Dent. 2012;25(6):315-20.

16. De Paula A, De Fúcio S, Alonso R, Ambrosano G, Puppin-Rontani R. Influence of chemical degradation on the surface properties of nano restorative materials. Oper Dent. 2014;39(3):E109-E17.

17. Smith R, Oliver C, Williams D. The enzymatic degradation of polymers in vitro. J Biomed Mater Res. 1987;21(8):991-1003

18. Park J, Song C, Jung J, Ahn S, Ferracane J. The effects of surface roughness of composite resin on biofilm formation of Streptococcus mutans in the presence of saliva. Oper Dent. 2012;37(5):532-9.

19. Sarkar NK. Internal corrosion in dental composite wear. J Biomed Mater Res Part A. 2000;53(4):371-80

20. Carvalho FG, Sampaio CS, Fucio SB, Carlo HL, Correr-Sobrinho L, Puppin-Rontani RM. Effect of chemical and mechanical degradation on surface roughness of three glass ionomers and a nanofilled resin composite. Oper Dent. 2012;37(5):509-17. doi: 10.2341/10-406-L.

21. Cornelio RB, Wikant A, Mjøsund H, Kopperud HM, Haasum J, Gedde UW, et al. The influence of bis-EMA vs bis GMA on the degree of conversion and water susceptibility of experimental composite materials. Acta Odontol Scand. 2014;72(6):440-7.

22. Castro HLd. Influence of brushing on a machined lithium disilicate-based ceramic: evaluation of maintenance of color and surface roughness. Rev Fac Odontol UPF. 2014;19(1). doi: 10.5335/rfo.v19i1.3634

23. Garcia LF, Mundim FM, Pires-de-Souza FC, Puppin Rontani R, Consani S. Effect of artificial accelerated aging on the optical properties and monomeric conversion of composites used after expiration date. Gen Dent. 2013;61:1-5.

24. da Silva EM, Goncalves L, Guimaraes JG, Poskus LT, Fellows CE. The diffusion kinetics of a nanofilled and a midifilled resin composite immersed in distilled water, artificial saliva, and lactic acid. Clin Oral investig. 2011;15(3):393-401. doi: 10.1007/s00784-010-0392-z.

25. da Silva EM, Dória J, da Silva JdJR, Santos GV, Guimarães JGA, Poskus LT. Longitudinal evaluation of simulated toothbrushing on the roughness and optical stability of microfilled, microhybrid and nanofilled resin-based composites. J Dent. 2013;41(11):1081-90.

26. Alrahlah A, Silikas N, Watts DC. Post-cure depth of cure of bulk fill dental resin-composites. Dent Mater. 2014;30(2):149-54. doi: 10.1016/j.dental.2013.10.011.

27. Kango S, Kalia S, Celli A, Njuguna J, Habibi Y, Kumar R. Surface modification of inorganic nanoparticles for development of organic-inorganic nanocomposites-A review. Prog Polymer Sci. 2013;38(8):1232-61. doi: 10.1016/j.progpolymsci.2013.02.003.

28. Oliveira DC, Souza-Junior EJ, Prieto LT, Coppini EK, Maia RR, Paulillo LA. Color stability and polymerization behavior of direct esthetic restorations. J Esthet Restorative Dent. 2014;26(4):288-95. doi: $10.1111 /$ jerd. 12113 .

29. Prodan DA, Gasparik C, Mada DC, Miclăuş V, Băciuţ M, Dudea D. Influence of opacity on the color stability of a nanocomposite. Clin Oral Investig. 2015;19(4):867-75.

30. Tan B, Yap A, Ma H, Chew J, Tan W. Effect of beverages on color and translucency of new tooth-colored restoratives. Oper Dent. 2015;40(2):E56-E65. 